\title{
March 9 Highlights
}

\section{Reduced cognitive functioning in carotid stenosis}

Mathiesen et al. examined neuropsychological performance in 189 subjects with asymptomatic carotid stenosis and 201 controls recruited from a population health study. Carotid stenosis was associated with poorer performance, independent of presence of silent MRI lesions.

see page 695

\section{Postictal psychiatric symptoms in partial epilepsy}

Kanner et al. found that postictal psychiatric symptoms with a median duration of 24 hours are relatively frequent in patients with refractory partial epilepsy. A psychiatric history is a risk factor for their occurrence. In addition, interictal psychiatric symptoms can worsen in severity postictally.

see page 708

"Postictal psychoses

The accompanying editorial by Michael

occurred in $7 \%$ of patients

... and were often as

disabling as the seizures

$$
\text { of epilepsy." }
$$

$R$. Trimble notes that postictal psychoses (PIP) usually emerge following a cluster of seizures, or an atypical seizure, and are distinct from immediate postictal confu-

sion. The latter is very common, and generally lasts only a few hours. In contrast, PIP usually emerges following a lucid interval, in which there are no obvious behavior changes, or at most quietening and social withdrawal, but then the psychosis escalates rapidly, with characteristic clinical features: minimal alteration of consciousness, delusions and hallucinations, and intense affect changes. Importantly, Kanner et al. found PIP in 7\% of their patients, which often was as disabling as the actual seizures of the epilepsy. PIP can be overlooked if not sought and the clinician is not aware of the lucid interval. Thirteen percent of the Kanner et al. sample expressed suicidal ideation; it is in this phase of the epilepsy that suicide may occur, especially if there is no clouding of consciousness and planned acts can be initiated.

see page 683

\section{Risk of multiple sclerosis in bereaved parents}

$\mathrm{Li}$ et al. studied the effect of parental bereavement on the risk of multiple sclerosis (MS). In a follow-up study based on several national registers in Denmark they found that psychological stress induced by the death of a child may play a role in the development of MS.

see page 726

\section{Parkinsonism in welders: Effect of levodopa}

Manganese can cause parkinsonism; however, how this entity can be differentiated from idiopathic Parkinson's disease is unclear. In the Koller et al. double-blind crossover study of 13 welders presumed to have manganese-induced parkinsonism, levodopa treatment provided no benefit vs placebo. This lack of responsiveness to levodopa may distinguish manganese-induced parkinsonism from PD.

see page 730

\section{Episodic migraine and chronic headache}

In a prospective study, Katsarava et al. assessed factors associated with the development of chronic headache $(>15 \mathrm{~d} / \mathrm{mo})$ prospectively in patients with episodic migraine. Over $14 \%$ of patients developed chronic headache within 1 year. Medication overuse and high attack frequency were the most important predictors.

see page 788

\section{Late-onset cerebellar ataxia, hypogonadism, and CoQ10 deficiency}

Gironi et al. report improved endocrinologic and neurologic findings after CoQ10 supplementation in two brothers with cerebellar ataxia/atrophy, hypergonadotrophic hypogonadism, and decreased muscle CoQ10.

see page 818 
Vertical oscillopsia in bilateral superior canal dehiscence syndrome
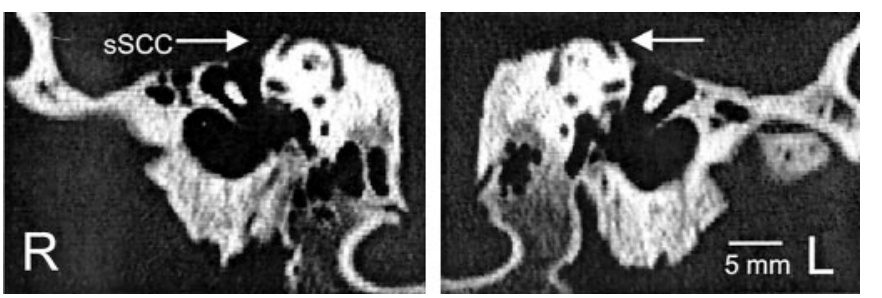

High-resolution CT images of the right and left temporal bones. Dehiscence of the bone covering the superior semicircular canal (sSCC) is indicated bilaterally.

The Deutschländer et al. study includes CT of temporal bones showing the lesion in the superior canal. The authors found that patients with bilateral superior canal dehiscence may suffer from vertical oscillopsia while walking. This oscillopsia may reflect bilateral anterior canal vestibular-ocular reflex impairment.

see page 784
The accompanying editorial by Robert W. Baloh tabulates the symptoms of the superior semicircular canal dehiscence syndrome and provides a well-illustrated explanation for the production of symptoms and signs: an internal perilymph fistula_ "a third window"-allows sound and pressure changes to displace endolymph in the anterior canal, deviating the cupula and exciting or inhibiting the anterior canal nerve. The diagnosis is made by triggering the characteristic torsional vertical nystagmus in the plane of the superior semicircular canal with either loud sounds (Tullio phenomenon) or pressure changes in the middle ear or CSF.

see page 684
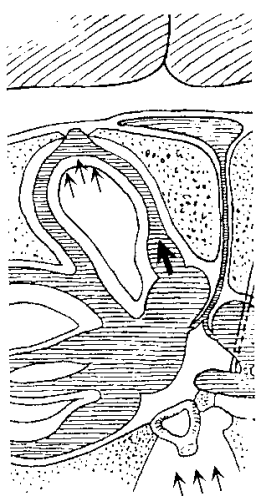

Normally, there are two windows in the bony capsule - the oval window (filled by the stapes foot plate) and the round window. A third window in the bony wall of the superior semicircular canal leads to vertigo and nystagmus with loud sounds or pressure changes in the middle ear or CSF. 


\title{
Neurology
}

\author{
March 9 Highlights \\ Neurology 2004;62;680-681 \\ DOI 10.1212/WNL.62.5.680
}

\section{This information is current as of March 8, 2004}

\section{Updated Information \&}

Services

Permissions \& Licensing

Reprints including high resolution figures, can be found at: http://n.neurology.org/content/62/5/680.full

Information about reproducing this article in parts (figures,tables) or in its entirety can be found online at:

http://www.neurology.org/about/about_the_journal\#permissions

Information about ordering reprints can be found online:

http://n.neurology.org/subscribers/advertise

Neurology ${ }^{\circledR}$ is the official journal of the American Academy of Neurology. Published continuously since 1951, it is now a weekly with 48 issues per year. Copyright . All rights reserved. Print ISSN: 0028-3878. Online ISSN: 1526-632X.

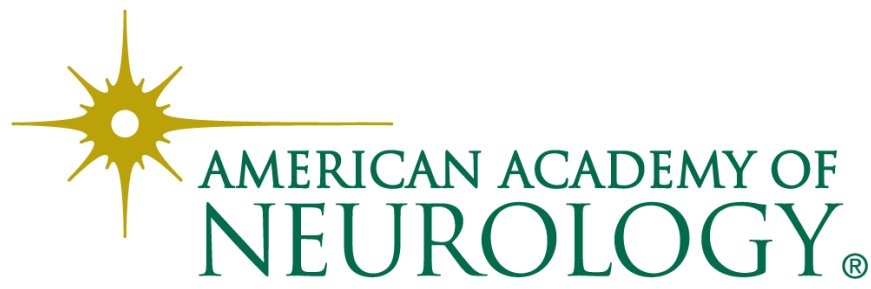

